\title{
CONDIÇÕES FACILITADORAS PARA IMPLANTAÇÃO DA GESTÃO DO CONHECIMENTO EM PROJETOS DO SEGMENTO OFFSHORE
}

\section{EASING CONDITIONS FOR KNOWLEDGE MANAGEMENT IMPLANTATION IN OFFSHORE SEGMENT PROJECTS}

\author{
Denise Terezinha Lisboa Bassani ${ }^{1}$; Manoel Franklin de Sá ${ }^{2}$; João Alberto Neves dos Santos ${ }^{3}$ \\ ${ }^{1}$ Universidade Federal Fluminense - UFF - Niterói -Brasil \\ denise.bassani@gmail.com \\ ${ }^{2}$ Universidade Federal Fluminense - UFF - Niterói - Brasil \\ franklin@predialnet.com.br \\ ${ }^{3}$ Universidade Federal Fluminense - UFF e UERJ- Niterói - Brasil e \\ Universidade do Estado do Rio de Janeiro - Resende - Brasil \\ joaoalbertoneves@gmail.com
}

\begin{abstract}
Resumo
A sofisticação do mundo atual exige de cada indivíduo um investimento interminável na busca do conhecimento, possibilitando-o a estar sempre inserido e a prosperar diante da agressiva competitividade no mercado de trabalho. Ampliando-se este enfoque do plano individual para o organizacional, observa-se que as pesquisas na área da Gestão do Conhecimento revestem-se de valor para os atuais gestores de negócios. Tal fato ocorre quando os últimos percebem como fator de sucesso, a riqueza do capital humano; o real ativo intangível da organização. A literatura especializada aponta diversas diretrizes e respectivas ferramentas que podem ser escolhidas pelos gestores para a orientação da implantação de um bem sucedido sistema de Gestão do Conhecimento. Neste sentido, este artigo focaliza a realidade gerencial de natureza impar reconhecida nos projetos em segmento offshore buscando identificar condições facilitadoras para a implantação de um sistema de Gestão do Conhecimento.
\end{abstract}

Palavras-chave: conhecimento, competências, petróleo e gás.

\section{Introdução}

A sofisticação do mundo atual exige de cada indivíduo um investimento interminável na busca do conhecimento, possibilitando-o a estar sempre inserido e a prosperar diante da agressiva competitividade no mercado de trabalho. No plano organizacional, observa-se que as pesquisas na área da Gestão do Conhecimento revestem-se de valor para os atuais gestores de negócios quando estes percebem, com fator de sucesso, a riqueza do capital humano; o real ativo intangível da organização. Este ativo intangível se forma através das diversas interações do conhecimento 
organizacional, quer seja através do compartilhamento de idéias visando adaptação dos colaboradores e a continuidade das rotinas produtivas de uma empresa; quer seja na busca de inovações, colocando a empresa na dianteira do mercado externo; ou seja, através do prisma da inteligência competitiva, objetivando tanto a defesa de seu capital intelectual quanto a busca para o pioneirismo em seu respectivo segmento de mercado. Partindo destas considerações, observam-se muitos segmentos produtivos onde é nítida a existência concreta ou em fase embrionária da interação destas três diretrizes a conduzir programas de gestão do conhecimento organizacional.

Entretanto, existem outros como o segmento offshore, caracterizado pelas fases de conceituação de projeto e fabricação de um bem de capital unitário, de alto valor, produzido especialmente de encomenda. No segmento offshore, observa-se que a importância da Gestão do Conhecimento requer uma abordagem exclusiva, por se tratar de indústria de mão-de-obra intensiva e altamente qualificada com suporte científico e tecnológico próprio. Ao observar este segmento em especial, este artigo tem como finalidade sugerir condições facilitadoras para a criação e implantação da Gestão de Conhecimento neste cenário ainda pouco conhecido dos estudos sob o enfoque da citada especialidade.

\subsection{O Problema}

Como campo da presente pesquisa, foi considerado o segmento offshore - exploração de petróleo e gás em águas profundas - cujo produto impõe às empresas contratadas para a construção e montagem de plataformas um esforço exclusivo, estendendo-se em cerca de dois a três anos. A contar do início do projeto até a entrega de uma plataforma em funcionamento.

Importante destacar a grandeza do produto relativo ao segmento offshore comparado a outros segmentos industriais cuja quantidade de produtos disponibilizados no mercado pode elevarse a milhares de milhões de unidades em produção diária, mensal ou anual. Além disto, o produto do segmento offshore requer necessariamente a contratação de alguns milhares de trabalhadores por projeto, com competências altamente diversificadas, tanto sob o aspecto dos seus conteúdos quanto aos níveis de profundidade e abrangência do conhecimento. O item sobre a contratação de recursos humanos intensamente diversificados em competências é revestido de uma característica importante e de difícil gerenciamento para as empresas montadoras: projetos constituem-se como organizações temporárias. Isto indica que as grandes equipes formadas por específicas competências dificilmente permanecem integralmente contratadas na mesma empresa após a entrega de uma plataforma, a não ser que exista uma ágil continuidade de projetos da mesma magnitude encomendados à empresa.

Observa-se que em vários segmentos produtivos, as empresas podem concentrar suas energias na implantação da Gestão do Conhecimento (doravante denominada GC) considerando três 
diretrizes, a saber: o compartilhamento de idéias, a inovação e a inteligência competitiva. A interação destas diretrizes produz um sistema que capacita às organizações a renovação constante de seus produtos, suas linhas de produção e componentes, uma vez que constroem um sistema observatório capaz de manter o conhecimento em níveis satisfatórios, capturar e realizar desejos do cliente e prospectar produtos a serem lançados futuramente no mercado. Todavia, no segmento offshore, onde é considerado primordialmente o trinômio preço-qualidade-prazo de entrega como condição fundamental nas avaliações de concorrências pelo cliente, a sistematização da GC deve ser considerada com a exclusividade que a natureza deste segmento determina. A GC necessita do enfoque sobre o conhecimento humano, suas competências exclusivas e específicas e em condições propícias para o seu desenvolvimento.

Desta forma pode estabelecer-se como método capacitando a organização a atingir a finalidade desejada, dentro dos recursos planejados, na qualidade determinada pelas normas e dentro do prazo determinado para entrega, com mínimo de retrabalho e desperdício de material e ainda conservando o capital intelectual da empresa ao máximo. Sobre este último aspecto, a conservação do capital intelectual - fundamentalmente o conhecimento humano existente na organização - trata-se de um dos fatores mais importantes a incidir sobre a construção do sistema de GC, pois os gestores devem considerar, no mercado dinâmico do segmento offshore, a alta rotatividade dos colaboradores contratados: estes, uma vez cientes de que foram contratados para trabalhar em um determinado projeto, também estão cientes que, ao finalizar este projeto, a possibilidade de serem conservados na organização vai depender do surgimento de novos contratos da mesma magnitude, o que nem sempre acontece.

\subsection{Objetivo do artigo}

A partir da abordagem do problema trazido à tona no item anterior e observando a escassez de relatos publicados abordando a prática da GC no segmento offshore, este artigo tem a pretensão de sugerir condições facilitadoras para a implantação da GC em projetos do já citado segmento industrial. Para elaborar este feixe de condições foram considerados vários tipos de especialização profissional requeridos para trabalhar em equipes coesas, compartilhando a visão, valores do projeto sendo também inerentes aos da empresa montadora, objetivando a entrega de um produto de grande magnitude e altíssimo valor dentro de um prazo exíguo. 


\subsection{Aspectos metodológicos}

A metodologia de pesquisa utilizada neste estudo é baseada em uma perspectiva exploratória: constitui-se na utilização de pesquisa bibliográfica, coleta de dados, observação e análise de verbalizações de profissionais desta área, principalmente a experiência advinda dos autores que participam ativamente deste segmento. Deve ser considerado o fato de que um dos autores detém observações conclusivas oriundas de sua função como Gestor de Contratos somando cerca de vinte e nove anos de experiência no segmento offshore.

Constatando a escassez de pesquisas acadêmicas sob o prisma da GC focalizando o segmento offshore, os dados coletados foram respaldados por extensa pesquisa bibliográfica abrangendo textos de autores nacionais e internacionais, dissertações, teses com base na GC estudada, sistematizada e praticada em ramos industriais análogos ao segmento offshore.

\section{Revisão da literatura}

\subsection{A construção do sentido da organização}

Ao se pensar na administração de qualquer empresa, mister se faz em construir uma fotografia da empresa identificando sua finalidade principal, suas riquezas e suas deficiências. O sensemaking, ou construção de sentido, tem como objetivo imediato "permitir aos membros da organização a construção de um entendimento compartilhado do que é a organização e o que ela faz.” (ALVARENGA 2008, pg. 79). O sensemaking traz a fotografia lúcida de uma empresa que possibilita aos componentes da organização mantê-la e adaptá-la aos movimentos incessantes e dinâmicos do mercado mundial. Conforme Alvarenga (2008) é fundamental a prospecção do ambiente organizacional externo para que informações sobre as tendências evolutivas deste mercado direcionem as ações internas.

Entretanto, há que ser lembrado o direcionamento fundamental do trinômio preçoqualidade-entrega no prazo nos projetos das construções offshore. Por este viés, compreende-se que as condições externas neste segmento de mercado são semelhantes para todos os concorrentes e o grande diferencial poderá ser a política organizacional interna. Cabe ressalvar que, apesar de a Diretriz Contratual dispor de informações comuns a todos os concorrentes, dificilmente identificase duas ou mais empresas que comunguem da mesma interpretação em relação ao disposto.

Alvarenga (2008, p. 80), em dado momento, afirma que o "nó górdio da construção de sentido das organizações" está na pergunta: “O que precisamos saber?” O presente estudo responde a esta questão apontando o mapeamento do conhecimento interno e das competências comprovadas 
pela equipe construtora, dado que as diretrizes fundamentais da construção do produto no segmento offshore estão delineadas no documento inicial de um projeto no segmento offshore: o Contrato celebrado entre a montadora e o cliente contendo detalhada apresentação do escopo de execução de serviços e seus correlatos requisitos.

Uma vez estabelecidas as diretrizes do Contrato, passa-se ao projeto, em seguida à construção e finalmente ao comissionamento, quando toda a plataforma passa por inspeções e testes até a entrega final da plataforma ao cliente.

Portanto a montadora apta a concorrer e ganhar um projeto da magnitude de uma plataforma, deve se assegurar quanto ao pleno domínio de conhecimento referente aos aspectos de projeto, condições de aquisições e suprimentos, procedimentos e processos de Construção e Montagem e domínio sobre as condições de partida da planta. Adiciona-se a imperativa necessidade em se dispor de mão-de-obra extremamente qualificada nas diversas competências que compõem as exigências fundamentais para tal empreitada.

\subsection{A importância das competências individuais}

O conceito sobre competência se revestiu de importância tanto nas discussões acadêmicas quanto nas práticas empresariais. Conforme brilhantemente pontuado por Fleury (2001), o termo "competência" tem sido utilizado no nível da pessoa (a competência do indivíduo); das organizações (core competences, designando as especialidades da empresa que efetivamente a colocam em posição competitiva no mercado) e no nível dos países (sistemas educacionais e formação de competências).

Na orientação de Zarifian (2001), “competência" significa a interação do conhecimento do indivíduo e sua utilização na prática das atividades de trabalho.

Fleury (2001) pondera sobre a conceituação da competência, buscando o enfoque do termo ao relacioná-lo ao conhecimento e prática detidos pelo indivíduo.

“... conceito de competência é pensado como conjunto de conhecimentos, habilidades e atitudes (isto é, conjunto de capacidades humanas) que justificam um alto desempenho, acreditando-se que os melhores desempenhos estão fundamentados na inteligência e personalidade das pessoas. Em outras palavras, a competência é percebida como estoque de recursos, que o indivíduo detém. [...]” (FLEURY, 2001, p. 184)

Os dois autores convergem ao definir que a competência se faz na própria ação do indivíduo orientado por um conhecimento específico da atividade que assume. 
Zarifian (2001) ao caracterizar o termo "competência", entrelaça a destreza do trabalhador apurada na prática de seu ofício com o conhecimento teórico previamente adquirido. Fundamentando-se nesta urdidura, o citado autor reveste a conceituação da competência com outras características, três delas aqui destacadas, pois são nitidamente reconhecidas e fundamentais no comportamento dos trabalhadores no segmento offshore: é o "assumir um trabalho", o "tomar iniciativa" e o "assumir responsabilidade".

A expressão "assumir um trabalho", conforme explanação de Zarifian (2001) aponta um novo tipo de envolvimento do indivíduo com a situação de trabalho bastante diferente do que era relatado em organizações de bases tayloristas. Trata do envolvimento do indivíduo com o seu trabalho, ainda que este seja delegado observando limites e obrigações em seu contrato de trabalho e seu campo de especialização.

Em seguida, a atitude caracterizada por "tomar iniciativa" demonstra que, quando alguém toma a iniciativa em uma situação de trabalho, prevista ou não, este alguém está raciocinando com base em conhecimento anterior para responder a algum evento. Zarifian (2001) esclarece que a tomada de iniciativa não se resume apenas a escolher uma ação recomendada em um repertório existente de normas. Este é o caminho adequado, mas, diante de um imprevisto, o trabalhador deve demonstrar a habilidade de criar uma solução adequada para conseguir o êxito. A tomada de iniciativa pressupõe conhecimento especializado formado no indivíduo, mas exige também a capacidade criativa que é característica do ser humano.

E, ao apontar a atitude de "assumir responsabilidade", o autor considera que, quando isto acontece, o trabalhador está, por extensão, respondendo não só por sua função, mas também pelo funcionamento de suas ferramentas, de seus instrumentos e pela responsabilidade pelos outros que interagem na mesma atividade ou no mesmo espaço físico. Considerando a complexidade dinâmica da construção de plataformas no segmento offshore, ao "assumir um trabalho", ao "tomar iniciativas" e ao "assumir responsabilidades", o trabalhador demonstra ter competências sólidas que permitem que ele assuma e cuide da integridade de seus equipamentos. Esta realidade existe tanto sob o aspecto da proteção patrimonial como sob o aspecto da segurança visando a sua própria integridade física e a dos seus companheiros e finalmente pela integridade ambiental.

A questão da responsabilidade assumida pelo trabalhador envolve "os objetivos de desempenho: prazo, qualidade, confiabilidade, satisfação do cliente.” (ZARIFIAN, 2001, p. 70).

Confirmando as palavras de Zarifian (2001), há que ser lembrado que um canteiro de obras offshore é regido pelas normas internacionais da Qualidade assim como as normas aplicáveis de Segurança, Meio ambiente e Saúde ocupacional, sendo os canteiros frequentemente inspecionados e auditados por profissionais qualificados oriundos de instituições certificadoras independentes. Ou seja, para o projeto offshore, não basta contar apenas com alguns profissionais destacados por sua 
formação acadêmica ou qualificação específicas em posições de chefia. Não, colaboradores, em sua generalidade, devem possuir competências caracterizadas tanto pelo conhecimento específico na modalidade profissional que representam quanto por sua prática demonstrada no campo e também quanto às atitudes em conformidade com as diretrizes da Qualidade, Segurança, Meio Ambiente e Saúde Ocupacional de um projeto, além do atendimento total e satisfatório às especificações do demandante do projeto. E Fleury (2001) complementa meticulosamente a explanação de Zarifian (2001) quando afirma que "competências são sempre contextualizadas", ou seja, pressupõem que os conhecimentos e o know how sejam urdidos numa rede de conhecimento e comunicação.

Ora, palmilhando o pensamento de Fleury (2001, p.187), dá-se primorosamente finalizada a definição de competência na afirmação de que a "noção de competência aparece assim associada a verbos como: saber agir, mobilizar recursos, integrar saberes múltiplos e complexos, saber aprender, saber engajar-se, assumir responsabilidades, ter visão estratégica.”. Confirmando a declaração da citada autora, observa-se que as competências, com o devido tratamento, beneficiam à empresa agregando-lhe valor econômico. E, da mesma forma ao indivíduo o valor social, pois amplia sua perspectiva de saber e, como conseqüência, sua imagem e confiabilidade perante a sociedade.

\subsection{Gerenciamento das competências}

\subsubsection{Formação do capital intelectual}

Seguindo-se às últimas considerações, a conclusão natural é de que o olhar sobre os recursos humanos necessários para a construção de um projeto offshore são determinantes para o seu sucesso. Cabe à organização compreender a forma de valorizar estes recursos e procurar mantê-los nos seus quadros administrativos, o que é uma árdua tarefa em tempos de aquecimento neste mercado de trabalho. Ou seja, o quadro de funcionários e respectivas competências especialmente desenvolvidas para um projeto offshore constitui-se efetivamente no ativo intangível que consistirá, ao lado dos recursos tecnológicos e científicos, no firme suporte para as obras de construção.

Oliveira Junior, M.M. (2001) observa que a função central da empresa é administrar este ativo intangível de forma a otimizar o desempenho organizacional. "O que vai determinar o sucesso da empresa é a sua eficiência nesse processo de transformação de conhecimento existente no plano das idéias para o conhecimento aplicado no plano das ações, em comparação com a eficiência de outras empresas." (KOGUT e ZANDER, 1993 apud OLIVEIRA JÚNIOR, 2001).

Ora, o ativo intangível de uma empresa conforme amplamente compreendido consiste naquilo que é denominado por Edvinsson e Malone (1998) como capital intelectual. E “o que é capital intelectual? Em termos simples, os ativos do conhecimento são talentos, habilidades, know- 
how, know-what e relacionamentos - assim como as máquinas e redes que os incorporam utilizados para criar riqueza. “(STEWART, 2002, p. 38).

O conhecimento permeia toda a realidade de uma empresa; o que compra, o que produz, como prospecta das necessidades do consumidor para assim vender mais. E, nos projetos offshore, não poderia ser diferente. "Capital intelectual é o conhecimento que transforma as matérias-primas e as torna mais valiosas." (STEWART, 2002, p. 40). Quando quatro ou cinco milhares de trabalhadores estão inseridos em um projeto offshore, utilizam as suas complexas e diferenciadas competências para construir - fisicamente - utilizando o intelecto para estudar desenhos, medir, conferir e comparar medições com instrumentos de precisão e, por fim, testar e colocar em funcionamento pleno toda a plataforma e entregá-la funcionando ao cliente. Portanto, na construção dos projetos offshore, há muito trabalho físico e mecânico a ser feito pela sua grande força trabalhadora, segmentada em equipes com funções e metas diversas. Porém, o conhecimento que conduz estes trabalhos é altamente especializado, diferenciado em escopo e níveis e o valor da gestão deste amplo e profundo conhecimento pode ser um fator crítico de sucesso para se atingir a meta imposta pelo trinômio preço-qualidade-entrega no prazo que direciona este tipo de projeto.

\subsubsection{Gestão do Conhecimento}

O que significa Gestão do conhecimento? Entre várias definições encontradas na bibliografia sobre a GC, optou-se pela que segue, devido à concisão e objetividade: "identificar o que se sabe, captar e organizar esse conhecimento e utilizá-lo de modo a gerar retornos" (STEWART, 2002, p. 172). Neste ponto cabe a ressalva de que, para identificar o que sabe e principalmente o que deverá captar, inicialmente a organização deverá ter uma noção exata do que é, quais os recursos tecnológicos e humanos pode dispor ou necessita dispor e o que deseja continuar fazendo para continuar a prosperar no mercado onde se insere.

\footnotetext{
Uma das falhas da gestão do conhecimento é o fato de muitas vezes não indagar que conhecimento gerenciar e para que finalidade. As atividades da gestão do conhecimento estão por todo o mapa: construção de bancos de dados, mensuração do capital intelectual, formação de bibliotecas corporativas, constituição de intranets, compartilhamento de melhores práticas, instalação de groupware, promoção de programas de treinamento, liderança de mudanças culturais, estímulo à colaboração, criação de organizações virtuais tudo isso é gestão do conhecimento e todos os líderes podem reivindicar sua participação nesse conjunto. (STEWART, 2002, p. 179)
}

A distinção entre conhecimento tácito e explícito, um dos fundamentos da obra de Nonaka e Takeuchi (1997) é fundamental para a construção da gestão do conhecimento no segmento 
industrial em questão. Considerando que o conhecimento tácito diz respeito ao conhecimento presente no indivíduo e não expressamente manifestado e o conhecimento explícito é o oposto, ou seja, é todo o conhecimento disponibilizado em forma escrita, em forma de textos, símbolos, desenhos, etc., observa-se que num canteiro de obras, os dois tipos de conhecimento interagem, se completam e podem se multiplicar gerando uma grande necessidade em serem administrados.

\subsection{Trabalhadores do conhecimento devem ser recompensados?}

São denominados "trabalhadores do conhecimento" aqueles que disseminam conhecimentos na empresa, independentemente das funções que nela desempenham. Sobre este aspecto, traz-se à tona a reflexão sobre recompensas, como recompensar e a quem sobre que serviços prestados. Tal reflexão aponta os trabalhadores do conhecimento como eleitos a serem recompensados de maneira hábil, de modo a se tornarem exemplos a serem copiados na empresa.

Entretanto, não se trata de modificar o sistema de méritos e recompensas de uma empresa, o que poderia impactar no seu equilíbrio financeiro, mas algo a ser feito de forma sutil. A organização deve considerar a advertência de Kohn (1998) sobre o risco em que varias organizações correm ao procurar recompensar todas as atitudes diferenciais positivas dos funcionários. Tal atitude cria expectativas além dos limites ou o fato de ter que lidar com descobertas aleatórias, rotinas que desviam a compreensão das necessidades reais da organização somente porque crescem as expectativas de recompensas no âmago dos trabalhadores.

Neste ponto, é originada a reflexão sobre como privilegiar condições organizacionais motivadoras de produtividade, onde a interação dos indivíduos seja fecunda em conhecimento, fortalecendo, com este objetivo, os meios de comunicação, socialização, confiança e auto-estima nos trabalhadores.

Kohn (1998) elege como fatores fundamentais que o administrador deve promover no ambiente de trabalhos os "três Cs" da motivação, "a saber, a colaboração, que define o contexto do trabalho, o conteúdo das tarefas e a extensão em que as pessoas têm alguma escolha (choice) sobre o que fazem e como o fazem" (KOHN, 1998, p. 199).

A colaboração pode ser considerada uma ferramenta de sucesso pois é fato que tarefas complexas, que podem exigir conhecimentos diversos serão executadas mais ágil e vitoriosamente se forem delegadas a equipes multidisciplinares do que se fossem delegadas a um indivíduo só. A colaboração cria sentimentos de entusiasmo e confiança onde ganham todos: a organização, o projeto e os trabalhadores, individualmente.

O conteúdo intelectual das tarefas a serem executadas deve promover o interesse dos trabalhadores, caso contrário, poderá haver um desvirtuamento causando preguiça, indiferença e 
irresponsabilidade (Herzberg, apud Kohn, 1998). A motivação é intrínseca ao sujeito quando o conteúdo interessa ao indivíduo e existe efetivamente o interesse quando este percebe que poderá exercer uma atividade que o alçará a patamares sociais mais altos: quer seja através de um novo aprendizado, quer seja através de conquistas de novas habilidades ou alguma variação de tarefa; enfim, tudo que pode produzir novas competências e oportunidades de demonstrá-las. A tarefa do líder administrativo será inicialmente na contratação de indivíduos com as devidas competências já formadas para o desempenho da atividade planejada, em primeiro lugar. E em segundo, o líder deve favorecer a comunicação com os subordinados de forma a conseguir as informações sobre aquilo que gostariam de fazer, além do que já fazem.

Quanto ao item ESCOLHA, significa prover oportunidades para que o indivíduo tenha a satisfação de tomar decisões. Mesmo em trabalhos como o presentemente enfocado, um líder deve se utilizar de sua função para comprometer os seus subordinados nas tomadas de decisão em conjunto. Os subordinados ficarão mais motivados e as rotinas laborais não exibem o pesado caráter de imposição; mesmo que, como é o caso da área foco do presente estudo, todas as atividades sejam milimetricamente planejadas, inspecionadas e comprovadas.

\subsection{Comunidades de prática: a ferramenta invisível da gestão do conhecimento}

As comunidades de prática são descritas por vários estudiosos da GC nas organizações: consistem em grupos de pessoas que se formam sempre em torno de assuntos de interesse comum a todas. A formação espontânea das comunidades de prática é observada em vários segmentos produtivos e no segmento offshore este fenômeno é percebido com clareza.

Segundo Wenger (1998), as comunidades de prática atravessam estruturas institucionais e hierarquias e podem perdurar por muito tempo depois de finalizado o motivo que as ocasionou. Podem ser encontradas:

- Dentro das empresas: surgem facilmente quando as pessoas procuram resolver problemas;

- Através dos setores da empresa: conhecimentos importantes são freqüentemente disseminados por unidades diferentes na empresa. Pessoas trabalham em equipes que permeiam várias funções, portanto formam comunidades de prática para manter contato com os seus informantes em várias partes da empresa e para manter a sua expertise.

Segundo Sabbag (2007), os benefícios percebidos em comunidades de prática em ambiente organizacional são:

- Tornam-se pontos de referencia para troca e interpretação de informações; 
- Permitem a retenção do conhecimento de maneira "viva" porque renovável. Conforme Wenger (1998), preserva o aspecto tácito do conhecimento muitas vezes não capturado pelos sistemas formais existentes na empresa. Segundo este autor, comunidades de prática são ideais para introduzir neófitos em alguma prática;

- Comunidades de prática podem forjar competências e apoiar-se mutuamente;

- Fornecem espaço para estabelecer identidade coletiva.

Embora as comunidades de práticas sejam observadas em maior quantidade no espaço virtual da Internet e Intranet, a formação de comunidades de prática que favorecem sobremaneira o desenvolvimento de competências de iniciantes é vista com freqüência nos canteiros de obras e assegurada por sentimentos de gratidão e amizade por aqueles que a compõem.

\section{Resultados}

\subsection{Considerações sobre as competências que compõem um projeto em segmento offshore}

A abordagem por competências se torna não só a mais recomendada metodologia para se iniciar a implantação de um sólido sistema de GC em projetos do segmento offshore, mas também a mais acertada e, seguramente, a mais prática.

Considerando os fundamentos teóricos explorados abordados no capítulo anterior, é de fundamental importância a consideração sobre os recursos humanos que compõem um time para construção e montagem de plataformas, compreendendo, mas não se limitando aos seguintes profissionais: Auxiliares (em todas as áreas), Almoxarifes, Analistas de sistemas, Encanadores, Engenheiros (especialistas em Elétrica, Eletrônica, Mecânica, Produção, Metalurgia, Química, Planejamento), Esmerilhadores, Especialistas em Gestão da Qualidade, em Segurança, em Recursos Humanos, em Contabilidade, Gasistas, Equipes do Controle da Qualidade (Inspetor de CQ em Dimensional, Inspetor de CQ em Elétrica / Telecom, Inspetor de CQ em Líquido penetrante, Inspetor de CQ em Partícula magnética, Inspetor de CQ em Pintura, Inspetor de CQ em Ultra-som, Inspetor de CQ Visual de solda, Inspetor de solda Nível 1, Inspetor de solda Nível 2), Maçariqueiros, Médicos, Montadores de estrutura metálica, Montadores de tubulação, Operadores de guindaste, Soldadores (em várias especialidades), Técnicos em desenho industrial, em manutenção, em documentação, em elétrica, em eletrônica, em enfermagem, em informática, em instrumentação, em mecânica, em metrologia, em pintura industrial, em planejamento, em soldagem, em telecom, em tubulação, Técnicos de área ambiental e outros.

Há que ser lembrado que, além da diferenciação das competências, estes profissionais compõem equipes formadas a partir da mesma especialidade técnica, onde existem posições de comando hierarquizadas conforme os níveis de responsabilidade profissional. São observadas 
equipes no campo chefiadas por encarregados, mestres, contra-mestres, supervisores, coordenadores até o Gerentes, Diretores, Superintendentes até a posição presidencial da empresa ou equivalente.

Para suporte ao mapeamento na fundamentação da Gestão do Conhecimento, sugere-se uma Matriz de Atribuições e Responsabilidades que seja construída pelas autoridades científicas do Projeto, ou seja, seus gerentes e diretores em conjunto com responsáveis pelo Departamento de Recursos Humanos. Este último se obrigará a cuidar do atendimento às determinações da Matriz que poderá servir de apoio para a descrição do perfil profissional de cada especialidade. Outra atribuição para o Setor de RH é a disponibilização da Matriz para conhecimento e orientação dos responsáveis pelos diversos setores que compõem o projeto em segmento offshore. Consta no Anexo I do presente artigo um modelo simples portando o mínimo de informações que uma Matriz de tal porte deve conter para se tornar uma ferramenta do mapeamento do conhecimento necessário a um projeto offshore.

A partir do preenchimento da Matriz com os dados inerentes a cada perfil, sugere-se uma extensão do sistema, agora contextualizado com os dados pessoais dos funcionários já admitidos e os equivalentes aos da Matriz. Caberá ao Setor de RH em conjunto aos responsáveis pelos setores a observação sobre o atendimento aos treinamentos internos dos procedimentos do Projeto relevantes aos diversos tipos de profissionais.

Da mesma forma, caberá ao RH a observação de lacunas de conhecimento onde a organização poderá prover aprendizagem aos colaboradores mediante a convergência de outras variáveis motivadoras, tais como continuidade de trabalhos em futuras plataformas na mesma empresa e mérito individual e por intermédio das ferramentas cabíveis da Gestão do Conhecimento.

\subsection{Condições facilitadoras para a manutenção e desenvolvimento do capital intelectual}

Considerando como capital intelectual o conhecimento apresentado pelos indivíduos tanto de forma tácita quanto explícita, a organização será bem sucedida na implantação de um sistema de GC mantendo-se sob o foco da abordagem pelas competências.

A GC, ao executar as ações que a definem - identificar, captar, organizar e disponibilizar o conhecimento presente nos indivíduos - deve se utilizar das ferramentas de suporte a seguir:

- Sistemas de avaliação de competências, bases de competências;

- Treinamentos visando socialização, adaptação dos recém-admitidos e funcionários transferidos visando o compartilhamento de idéias, diretrizes, metas e missão da empresa, assim como sobre procedimentos em forma explícita, já validados pelas autoridades científicas da organização; 
- Suporte informatizado para disponibilizar dados em níveis de profundidade e amplitude, considerando as competências individuais que precisam acessar tais informações;

- Palestras, seminários, cartazes e todos os recursos áudio-visuais;

- Bibliotecas;

- Estágios para novos trainees;

- Tratamento e disponibilização das Lições Aprendidas.

A utilização destas ferramentas é determinada pelas necessidades e recursos da organização. Porém, os gestores alinhados ao conceito da GC devem atentar para a relevância das comunidades de prática, mormente no segmento offshore onde é notória a criação e continuidade de comunidades de prática, onde veteranos são respeitados como mestres, pela generosidade com que transmitem conhecimentos aos iniciantes traduzindo-se no ingresso a novas profissões para aqueles ainda não favorecidos por qualificações profissionais.

\section{Conclusão}

O segmento offshore demanda profissionais de alto nível de especialização, em nível universitário ou técnico. Especialização que pode não exigir a formação universitária, mas exige, em muitos dos casos, cursos especializados, como por exemplo, os que provêem qualificações para várias especialidades que compõem uma equipe de Controle da Qualidade. Nos perfis profissionais onde é identificada a ausência de obrigatoriedade de certificados e qualificações como pré-requisito para admissão, esta ausência é substituída pela exigência da prática comprovada e demonstrada. Sendo assim, é percebido que muitos profissionais aumentam o seu conhecimento a cada projeto em que trabalham, terminando, após alguns projetos finalizados, como grandes profissionais em seu campo de especialização.

Portanto, a organização que percebe esta seqüência de acontecimentos, pode e deve se beneficiar do movimento dinâmico do conhecimento interno, favorecendo a sustentabilidade de ambiência de colaboração, confiança e determinação.

A conceituação de "competência" é perfeita para identificar planos onde se inserem os especializadíssimos profissionais do segmento offshore. É importante lembrar que, diante das rotinas de trabalho não só de construção e montagem, mas de inspeções e testes, muitas vezes o líder da equipe se encontra em local distante de seus subordinados. E, diante de situações imprevistas, componentes da equipe precisam tomar decisões imediatas, muitas delas envolvendo riscos para a vida ou para o bem patrimonial; assim como riscos ambientais. Nestes casos, é 
favorecido também o posicionamento do líder, que embora distante, deve estar pronto a dar o suporte necessário.

A utilização de todos os recursos da informática é condição sine qua non para a sustentabilidade de um sistema de GC. Hoje em dia, o acesso à rede Web e a utilização dos computadores pessoais é fato corriqueiro em qualquer empresa. Entretanto, ressalva-se que os trabalhos no segmento offshore estão nos ombros de milhares de trabalhadores que passam a maior parte de sua rotina diária no campo, ao ar livre. Estes, ainda que consultem computadores, redes para receber conhecimentos teóricos, devem comprovar suas competências firmadas no dia-a-dia em trabalhos manuais, braçais até artesanais, no tocante a muitos, como por exemplo, os soldadores. E então, a utilização da competência, a disseminação e apreensão do conhecimento tácito são fortemente observadas sem o suporte de recursos eletrônicos.

Este estudo conclui que o ambiente onde pode prosperar a implantação de um sistema de Gestão do Conhecimento em segmento offshore denota condições facilitadoras de aspecto qualitativo. Nestas condições, percebe-se o valor da motivação intrínseca do colaborador, que pode ser sutilmente estimulada por um líder sensível a prover atividades com conteúdo interessante, estimulando o trabalhador a escolher o melhor método. Desta forma o líder estará habilmente fortalecendo as competências de seus subordinados ao fortalecer suas atitudes e responsabilidades perante o trabalho, sua integridade física, seus equipamentos e ferramentas, seus colegas e o ambiente de trabalho. Tal líder deve ser um profissional adequadamente competente, lidando com colaboradores de competências também adequadas e comprovadas, ativadas pelas situações imprevistas muitas vezes margeadas pelos riscos de segurança, saúde e ambientais inseridos em contexto pleno de colaboração.

\begin{abstract}
The sophistication of world nowadays demands an endless investment from each person about seeking knowledge for providing one of being inserted and prosperous into the job market aggressive competitiveness. On extending such focus from individual to organizational level, it is being observed that Knowledge Management researches are of great value for business managers. Such fact happens when managers observe the human capital richness as a success factor; the real organizational intangible assets. The specialized literature points several directions and respective tools that can be chosen by managers as guides for implanting a successful Knowledge Management system. Following such perspective, the present article focuses the unique nature of the offshore segment projects managerial reality, seeking to identify easing conditions for implanting a Knowledge Management system.
\end{abstract}

Key-words: knowledge, competences, oil and gas.

\title{
Referencias
}

ALVARENGA NETO, Rivadávia C. Drummond de. Gestão do Conhecimento em organizações: proposta de mapeamento conceitual integrativo. São Paulo: Saraiva, 2008;

BOOTH, Wayne C. COLOMB, Gregory G., WILliAMS Joseph M. A arte da pesquisa, Tradução de Henrique A. Rego Monteiro. São Paulo: Martins Fontes, 2000. 
COOPER, Donald R.; SCHINDLER Pamela S. Métodos de Pesquisa em Administração. Porto Alegre: Bookman, 2003.

CAVALCANTI, Marcos; NEPOMUCENO, Carlos. O conhecimento em rede: como implantar projetos de inteligência coletiva - Rio de Janeiro: Elsevier, 2007.

DAVENPORT, Thomas, PRUSAK, Lawrence. Conhecimento Empresarial. São Paulo: Ed. Campus, 1999.

DRUCKER, Peter. Sociedade Pós-Capitalista. Tradução autorizada do idioma inglês da edição publicada por Harper/Collins, New York, N.Y. Tradução de Nivaldo Montingelli Jr. São Paulo: Publifolha, 1999.

EDVINSSON, Leif; MALONE, Michael S. Capital Intelectual. São Paulo: Makron Books, 1998.

FERRAZ, João Carlos, et al. Estudo da Competitividade de Cadeias Integradas no Brasil: Impactos das zonas de livre comércio. Cadeia: Indústria Naval. Campinas, SP: UNICAMP, 2002. Disponível em: http:/www.desenvolvimento.gov.br/arquivo/sdp/proAcao/forCompetitividade/impZonLivComercio/24navalCompleto. pdf Acesso em agosto/2005.

FleUry, M. T. L.; FleURY, A. Construindo o conceito de competência. Revista de Administração Contemporânea, v. 5, edição especial, p. 183-196, 2002.

FULD, Leonard. Inteligência Competitiva. Trad. Janaína Ruffoni. Rio de Janeiro, Elsevier, 2007.

GARVIN, David A. Construindo a Organização que Aprende. Harvard Business Review, Julho-Agosto 1993 in Gestão do Conhecimento - Harvard Business Review, Trad. Afonso Celso da Cunha Serra. Rio de Janeiro: Campus, 2000 .

GOMES, Elisabeth; BRAGA, Fabiane. Inteligência competitiva - Como transformar informação em um negócio lucrativo. $2^{\text {a }}$ Ed. Rio de Janeiro: Elsevier, 2004.

KLEIN, David A. A Gestão Estratégica do Capital Intelectual. Rio de Janeiro: Qualitymark, 1998.

LÉVY, Pierre. Cibercultura. Tradução de Carlos Irineu da Costa. - São Paulo: Ed. 34, 1999.

NONAKA, Ikujiro, TAKEUCHI, Hirotaka. Criação de conhecimento na empresa. Tradução de Ana Beatriz Rodrigues, Priscilla Martins Celeste. Rio de Janeiro: Campus, 1997.

NONAKA, Ikujiro, TOYAMA, Ryoko, NAGATA, Akiya - A firm as a Knowledge-creating Entity: A New Perspective on the Theory of the Firm - Industrial and Corporate Change, Volume 9 Number 1, 2000. Oxford University Press 2000.

OLIVEIRA JÚNIOR, M.M. Competitividade Baseada no Conhecimento. In CAVALCANTI, M. Gestão Estratégica de Negócios evolução, cenários, diagnóstico e ação. São Paulo: Pioneira, 2001.

PROBST, Gilbert. RAUB, Steffen e ROMHARDT, Kai - Gestão do Conhecimento: os elementos construtivos do sucesso. Porto Alegre, Bookman, 2002.

QUINN, James B., ANDERSON, Philip e FINKELSTEIN, Sydney. Gerenciando o Intelecto Profissional: Obtendo o Máximo do Melhor, In: A Gestão Estratégica do Capital Intelectual. São Paulo: Quality Mark,1998, reproduzido com permissão da Harvard Business Review de "Managing Professional Intellectual: Making Most of the Best" de James Brian Quinn et al, março-abril 1996, pp 71-80.

RODRIGUEZ, Martius Vicente Rodriguez y. FERRANTE, Agustín J. Tecnologia de Informação e Gestão Empresarial. Rio de Janeiro: E-papers, 2000.

; LOUREIRO, Juliano; VIEIRA, Rita. Gestão Estratégica de Recursos Humanos. Rio de Janeiro: Qualitymark: PETROBRAS, 2005.

SABBAG, Paulo Yazigi. Espirais do Conhecimento - Ativando indivíduos, grupos e organizações. São Paulo: Saraiva, 2007.

SCHÖN, Donald A. Educando o Profissional Reflexivo - um novo design para o ensino e a aprendizagem. Trad. 
Roberto Cataldo Costa. Porto Alegre: Artes Médicas Sul, 2000.

SENGE, Peter. A Quinta Disciplina. 3.ed. São Paulo: Best Seller, 1998.

SVEIBY, Karl-Erik. Gestão do Conhecimento - A lição dos Pioneiros. Janeiro, 2001. Disponível em http://www.jrbrands.com.br/PDFs/KnowledgeManagementPort Acesso em: dezembro/2004.

STEWART, Thomas A. A riqueza do conhecimento: o capital intelectual e a organização do Século XXI. Tradução de Afonso Celso da Cunha Serra. Rio de Janeiro: Campus, 2002.

VALENTIM, Marta Lígia Pomim. Inteligência Competitiva em Organizações: dado, informação e conhecimento. DataGramaZero - Revista de Ciência da Informação - v.3 n.4 ago/02 ARTIGO 02. Disponível em http://www.dgz.org.br/ago02/Art 02.htm acesso em agosto 2007.

O Processo de Inteligência Competitiva em Organizações. DataGramaZero - Revista de Ciência da Informação - v.4 n.3 jun/03 ARTIGO 03. Disponível em http://www.dgz.org.br/jun03/Art_03.htm acesso em agosto 2007

VON KROGH; George, ICHIJO, Kazuo; NONAKA, Ikujiro. Facilitando a Criação de Conhecimento: reinventando a empresa com o poder da inovação contínua. Tradução de Afonso Celso da Cunha Serra. - Rio de Janeiro: Campus, 2001.

WENGER, Etienne. Communities of Practice: Learning as a Social System. Publicado em "The Systems Thinker", Vol. 9, No. 5 Junho 1998. Disponível em http://www.ewenger.com/pub/pub_systems_thinker_wrd.doc Acesso em: março/2006

ZARIFIAN, Philippe, Objetivo Competência: Por Uma Nova Lógica, Tradução Mª Helena C. V. Trylinski. - São Paulo: Atlas, 2001. 
ANEXO I

Matriz de Atribuições e Responsabilidades

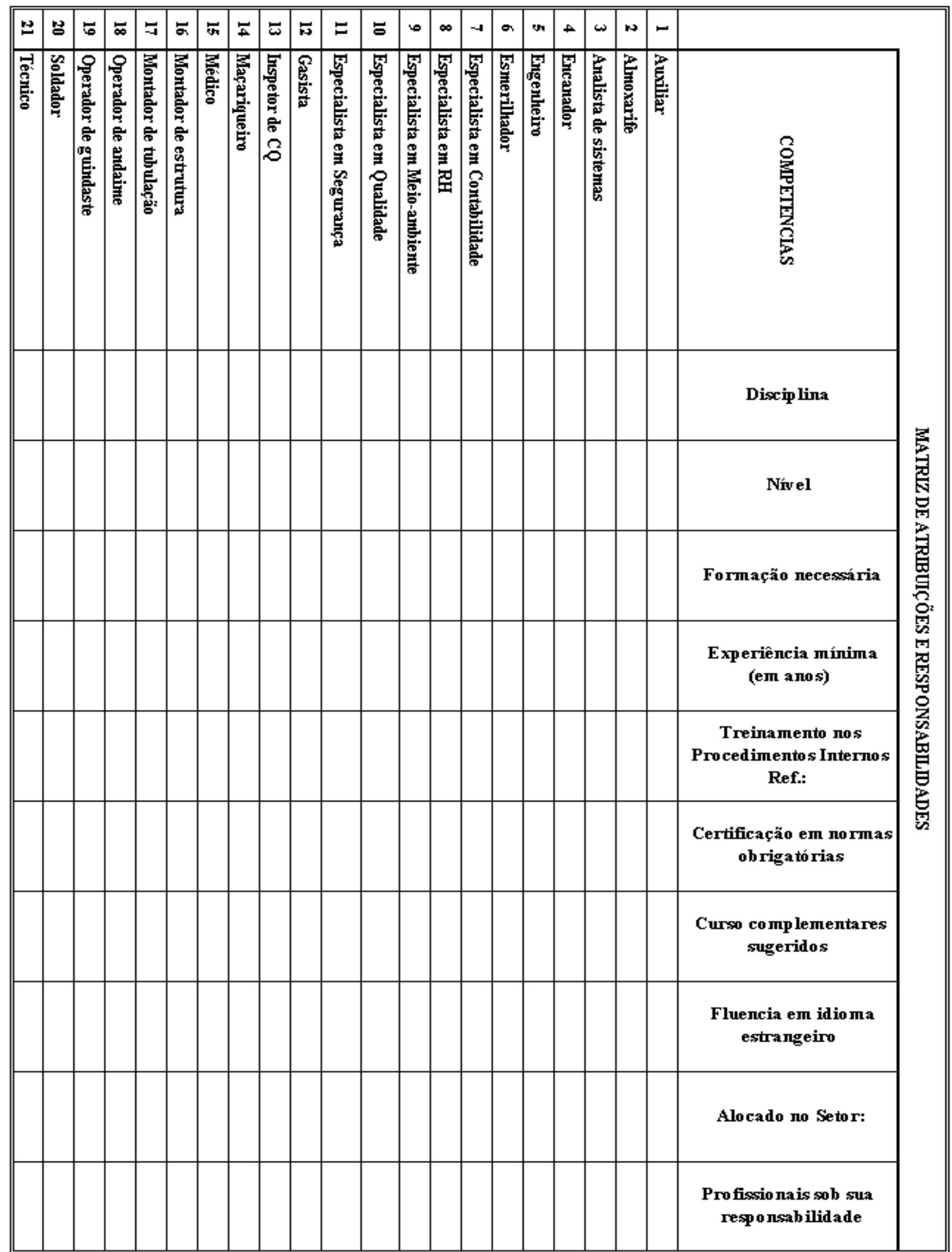




\section{Dados dos autores:}

\section{Nome completo: Denise Terezinha Lisboa Bassani}

Filiação institucional: Mestre em Sistemas de Gestão pela Universidade Federal Fluminense, MBA em Gestão pela Qualidade Total no LATEC / Universidade Federal Fluminense.

Função ou cargo ocupado: Professora universitária / MBA lecionando sobre Gestão do Conhecimento

Endereço completo para correspondência (bairro, cidade, estado, país e CEP): Rua Gen. Pereira da Silva, nº 125,apto. 502 - Icaraí - Niterói - RJ - Brasil - CEP: 24220-030

Telefones para contato: (21) 2714-8916; (21) 9605-6100

e-mail: denise.bassani@gmail.com

\section{Nome completo: Manoel Franklin de Sá}

Mestre em Sistemas de Gestão pela Universidade Federal Fluminense, Pós-Graduado em Gerenciamento de Projetos - FGV, Gestão de Negócios em Petróleo e Gás - FGV, e Organizações e Estratégias pela UFF. Graduado em Engenharia pela UCP/RJ,

Função ou cargo ocupado: Professor Universitário - MBA / lecionando disciplinas relacionadas a Gerenciamento de Projetos

Endereço completo para correspondência (bairro, cidade, estado, país e CEP): Rua Álvares de Azevedo, nº 97, apto. 804 - Icaraí - Niterói - RJ - Brasil - CEP: 24220-020

Telefones para contato: (21) 2526-8519; (21) 8259-8543

e-mail: franklin@predialnet.com.br

\section{Nome completo: João Alberto Neves dos Santos}

Graduação em Engenharia Mecânica pelo Instituto Militar de Engenharia (1989), mestrado em Sistemas e Computação pelo Instituto Militar de Engenharia (1993) e doutorado em Engenharia de Produção pela Pontifícia Universidade Católica do Rio de Janeiro

Função ou cargo ocupado: professor adjunto da Universidade do Estado do Rio de Janeiro, Diretor do Campus Regional de Resende e da Faculdade de Tecnologia da UERJ e professor colaborador da Universidade Federal Fluminense

Endereço completo para correspondência (bairro, cidade, estado, país e CEP): Universidade do Estado do Rio de Janeiro, Km 298, Pólo Industrial, Resende - RJ - Brasil - CEP: 449068607-15 Telefones para contato: (24) 3354-7875

e-mail: joaoalbertoneves@gmail.com 